Thélème. Revista Complutense de Estudios Franceses ISSN-e: 1989-8193

http://dx.doi.org/10.5209/THEL.62923

\title{
From addition to concession: Hebrew gam 'also'
}

\author{
Hava Bat-Zeev Shyldkrot ${ }^{1}$, Hagit Shefer ${ }^{2}$ \\ Recibido: 27/02/2019/ Aceptado: 29/04/2019
}

\begin{abstract}
This article investigates the internal structure of the Hebrew particle gam ("also") from the perspective of construction grammar. Hebrew gam seems to exhibit meanings of both addition and concession, as a single particle and through compounds such as ma gam ("all the more so"), gam kaxa ("as it is") and gam im ("even"). The findings reveal that the interpretation of the various meanings realized by the construction result from the interaction of syntactic, semantic and pragmatic factors which in turn lead to a form-meaning pairing associated with conventional meanings. The article argues that gam functions as a partly- schematic construction which displays non-discrete meanings ranging from addition at one end of a continuum through polysemous cases which display both addition and concession to concession at the other end of the continuum.
\end{abstract}

Keywords: addition; concession; continuum; construction grammar; polysemy.

\section{[fr] De l'addition à la concession: le cas de l'hébreu gam « aussi »}

Résumé. Cet article se propose d'examiner la structure interne de la particule hébraïque gam («également, aussi ») du point de vue de la grammaire de construction. En Hébreu le marqueur gam introduit à la fois l'addition et la concession, aussi bien en tant que particule unique que dans des composés tels que ma gam ("à plus forte raison »), gam kaxa (« même comme ça ») et gam im (" même si »). Un examen minutieux révèle que l'interprétation des différentes significations de cette construction résulte de l'interaction de facteurs syntaxiques, sémantiques et pragmatiques, qui à leur tour conduisent à un appariement forme-sens associé aux significations conventionnelles. L'article soutient que gam fonctionne comme une construction en partie schématique qui affiche des significations non discrètes allant de l'addition à une extrémité du continuum à la concession à l'autre extrémité du continuum en passant par des cas polysémiques qui affichent à la fois addition et concession.

Mots clé : addition; concession; continuum; grammaire de constructions; polysémie.

\section{[es] De la adición a la concesión: el caso del hebreo gam "también"}

Resumen. El presente artículo investiga la estructura interna de la partícula hebrea gam ("también") desde la perspectiva de la gramática de construcciones. El marcador gam del hebreo parece exhibir tanto significados de adición y de concesión como una sola partícula, y a través de compuestos tales como ma gam ("tanto más"), gam kaxa ("también así") y gam im ("aun cuando"). Los hallazgos de la investigación muestran que la interpretación de los diversos significados de esta construcción resultan de la interacción de factores sintácticos, semánticos y pragmáticos que, a su vez, conducen a un emparejamiento forma-significado asociado con significados convencionales. El artículo sostiene que gam funciona como una construcción parcialmente esquemática que muestra significados no discretos que van desde la adición en un extremo de un continuum hasta los casos polisémicos que señalan tanto la adición y la concesión como la concesión en el otro extremo del continuum.

$1 \quad$ Tel Aviv University. Tel Aviv University.

hbzs22@tauex.tau.ac.il

2 Beit-Berl Academic College.

hagit.shefer@beitberl.ac.i 
Palabras clave: adición; concesión; continuo; gramática de construcciones; polisemia.

Summary. 1. Introduction. 2. Theoretical background. 2.1. Construction grammar. 2.2. Addition and concession. 2.3. General category continuity. 3. Analysis of the construction gam. 3.1. Additive meaning. 3.2. Intermediate cases. 3.3. Concessive meaning. 4. Conclusion.

Cómo citar: Bat-Zeev Shyldkrot, H. \& H. Shefer. (2019). "From addition to concession: Hebrew gam 'also'”. Thélème. Revista Complutense de Estudios Franceses. Vol. 34, Núm. 1: 29-45.

\section{Introduction}

It has long been acknowledged that a traditional classification of language into discrete categories often cannot account for a growing body of phenomena which point to an overwhelming prevalence of a non-discrete continuous structure of language ${ }^{3}$. Researchers have identified a cross-linguistic characteristic according to which semantic, syntactic and functional categories including a wide variety of linguistic phenomena often display gradualness, overlap and continuity.

Support of a non-discrete nature of linguistic structure may be found in a variety of studies regarding categorization. A partial exemplification would begin with prototype theory (Rosch, 1973; Filmore, 1975), hierarchy of categories (Ross, 1972; 1973), components of grammar and in particular morphology (Anderson, 1982), and a partial overlap of semantic categories such as contrast, condition, concession and temporals (Quirk et al., 1985; Harris, 1986; Harris, 1988; Bat-Zeev Shyldkrot, 1995; 2001). More recent evidence of a continuous structure of language is found in other research areas. For example, construction grammar (Goldberg, 2006; 2013), grammaticalization (Traugott, 2010; Traugott \& Trousdale, 2013) and subjectivity and subjectification (Athanasiadou, 2007; Narrog, 2017), all of which agree on a scalar, gradual and continuous view of the structure of language.

Along these lines, the goal of this paper is to investigate the Hebrew particle gam (also) from the perspective of functional construction grammar (Noel, 2007; Goldberg, 2013; Croft \& Cruse, 2004) aiming to broaden the view that language forms a continuum. We further argue that Contemporary Hebrew gam constitutes a partly-schematic construction containing a substantive element gam which is combined with different lexical items and creates several variants. The different realizations display non-discrete meanings ranging from addition at one end of a continuum to concession at the other end. Adopting the framework of construction grammar, the construction is viewed here as a pairing which conventionally associates a form with a meaning. We argue that the interpretation of the different variants results from an interaction of semantic, syntactic and pragmatic factors and that this interaction constitutes part of the linguistic knowledge of speakers of Hebrew.

\section{Theoretical background}

\subsection{Construction grammar}

As suggested in the introduction, we will show that the interaction of the various syntactic, semantic and pragmatic properties displayed by instances of Contemporary He-

See more on the issue of non-discrete categories in van Goethem, Norde, Coussé \& Vanderbauwhede (2018). We have learned about the publication of this book while the article was already in press. 
brew gam can be best demonstrated within the framework of construction grammar. Research on a variety of linguistic phenomena has found construction grammar an appropriate framework for a description of form-meaning pairings in varying degrees of size, shape, complexity and schematicity (Goldberg, 2006; 2013; Hoffmann \& Trousdale, 2013; Croft \& Cruse, 2004; Noël, 2007).

Construction grammar includes several related approaches to language 4 . Berkeley Construction Grammar as developed by Charles Fillmore (1988) emphasizes the idea that both core and peripheral phenomena can be described and explained by the same mechanisms. This approach pays special attention to idiosyncratic expressions such as let alone or what's $X$ doing $Y$. According to this approach, idiomatic expressions exhibit syntactic and semantic properties which are not fully derivable from more general constructions and which are characteristic only of a particular idiomatic construction. Cognitive Construction Grammar was developed by George Lakoff and Adele Goldberg among others (Lakoff, 1987; Goldberg, 1995; 2003; 2006). This variant focuses on providing a psychologically plausible description of language by examining cognitive principles which underlie constructions and their organization in a network, and emphasizes the non-predictability of the meaning of a construction from its components. Radical Construction Grammar which was developed by William Croft (2001) is concerned with the relationship between grammatical description and language typology. Accordingly, "constructions are language-specific and categories are defined language-specifically in terms of the constructions they are in" (Traugott \& Trousdale, 2013: 6). The last approach to be reviewed is Cognitive Grammar which was developed by Ronald Langacker $(2008,2013)$. It shares many assumptions with other constructionist frameworks, but its basic assumptions are that language is grounded in embodied human experience and that grammar is inherently meaningful. Language is viewed as a system of form-meaning pairings which consist mainly of semantic and phonological poles and less of syntactic information.

The difference between the various approaches is often not obvious. For example, some would argue that Lakoff's approach is closer to Fillmore's than to Goldberg's approach. Others suggest that Langacker's view on language is closer to Lakoff's. Despite differences among the various constructionist approaches, several common tenets are identified. The important ones are that the basic unit of grammar is a conventional form-meaning pairing i.e. a construction. In addition, "semantic structure is mapped directly on to surface syntactic structure, without derivations" (Traugott \& Trousdale, 2013: 3). Third, language is organized in a network of inheritance hierarchies which captures the way properties of lower level constructions can be predictable from more general ones. The principal claim of this framework, which is most relevant to this study, is that a description of a construction's behavior can be complete only if it provides a holistic account of all the features participating in tandem in conveying meaning, including phonology, semantics, syntax and pragmatics 5 .

Based on Croft \& Cruse (2004), Hoffmann \& Trousdale (2013) and Traugott \& Trousdale (2013).

For the influence of pragmatic features in the interpretation of constructions see for example Shefer (2018), Hilpert (2014), Goldberg \& van der Auwera (2012) and Kay (2004). 


\subsection{Addition and concession}

In order to demonstrate both the additive and concessive interpretation of gam, this section first defines the two terms and reviews some of the literature pertaining to these semantic categories. Concerning addition, Quirk et al. (1985: 634) identify seven conjunctive categories. Among these, we find the category listing which consists of two sub categories, namely enumerative and additive. Examples of enumerative adverbs include first, second, for one thing, to begin with, next, and last, all of which prioritize a specific item on a list of items. Additive adverbs are further divided into equative and reinforcing adverbs. Equative adverbs include for example, correspondingly, equally, likewise, similarly, in the same way and by the same token. These adverbs convey the message that an item has an equal or a similar force to a preceding one. Reinforcing adverbs include again, also, besides, further, moreover, then, in addition, what is more and above all. These adverbs attribute a greater force or weight to an item on a list.

The semantic category of concession is particularly versatile. Including a wide variety of markers such as although, despite, even, nevertheless, and even though, it has been investigated in numerous studies and from a variety of perspectives (Soutet, 1990; 1992). Studies focus on different aspects and propose different definitions, but all seem to suggest that the category exhibits some overlap with other categories, in particular conditionality and contrast (Harris, 1986; 1988), but also time and addition (Quirk et al., 1985). Explaining the structure of various categories often relies on a syntactic description of a variety of symmetrical and asymmetrical relations which are defined in terms of a satellite and a nucleus. A concessive utterance is said to include a subordinating clause which functions as a satellite and a main clause which functions as the nucleus (Mann \& Thompson, 1988; Kong, 2014).

Regarding the semantic definition of concession, it is mostly viewed as unexpectedness of the situation in the matrix in the light of the situation described in the concessive clause (Quirk, 1985), or incompatibility between antecedent and consequent (König, 1985). Rudolph (1996) suggests that two states of affair stand in contrast so that one implies a different fact from the other or functions as an obstacle to the realization of the other as in Although I am tired, I shall go to the festival.

Hebrew concession is discussed in several studies. Zusman (2013) analyzes three types of Hebrew concession, specifically denial of expectation, a rhetorical strategy and a change in direction of argument. Azar (1999) distinguishes between direct and indirect concession. Accordingly, direct concession explicitly states that an expected result did not happen whereas indirect concession presents an explanation from which one can infer that the expected result did not happen. Livnat (2010) examines concessive relationships in Hebrew on a sentence level and on a discourse level, and proposes that concession is the opposite of a causal relationship. Accordingly, whereas "a causal relationship establishes a causal relation between two parts of an utterance, a concessive relationship determines that despite an expected causal relationship between the two parts, this relationship does not hold and in fact the opposite of the expected is observed" (Livnat, 2010: 85). In terms of the syntactic relation between the two clauses, it is either subordination or coordination, but the logical relation is always subordination. Livnat further argues that concession has several argumentative purposes, a few of which are establishing the importance of a 
research field, justification of research methods, theoretical framework, interpretation of findings, innovation and conclusion ${ }^{6}$.

\subsection{General category continuity}

Many researchers discuss the idea that markers of one category may display continuity and overlap with markers of other categories, in particular those of concession, contrast and conditionals but also time and addition. Harris $(1988,1986)$ maintains that there exists a

semantic spectrum ranging from causal clauses in which the causal link between subordinate and main clause is asserted, via conditional clauses, in which the causal link is hypothesized and proposed as a basis on which to continue the verbal interaction, to concessive clauses, in which the causal link between protasis and apodosis is denied (Harris, 1988: 71).

A further extension of this spectrum suggests that hypothetical concessives are connectives which have developed from conditional to concessive conditionals ( $\mathrm{Ru}-$ dolph, 1996: 212). These connectives operate within a spectrum which ranges from concessives to conditionals and share semantic features with both categories. The conditional concessive even if combines the concessive force of even and the conditional force of if. Compared to even though for example, which presupposes the proposition in the satellite, even if leaves the option open (Quirk et al., 1985: 1099) ${ }^{7}$. Harris (1988: 74) further describes the function of even if as marking an extreme value within a set of possibilities which is incompatible with the consequent.

The categories of time and addition also seem to partly overlap with other categories. For example, a temporal marker such as when can also show concession as in They were gossiping when they should have been working (Quirk et al., 1985: 1085). Also suggested is that even which regularly signals concession can function as an additive subjunct to signal addition as in I've noticed the fox in my garden and John has also/even seen it near his back door (p. 609). From the opposite direction, the authors suggest that and, which regularly signals addition can be interpreted to signal condition as in Give me some money, and I'll help you escape (p. 931).

The overlap between semantic categories is observed in Hebrew too. Some Hebrew markers are explicitly concessive markers whereas others function to signal both concession and contrast (Livnat, 2010: 92). The markers which signal explicit concession convey a clear message of argumentative rejection of the proposition introduced by the satellite while the second type displays a symmetrical relation between propositions of an identical status, thereby marking "weaker" concession, as stronger importance is attributed to the satellite and it is not easily rejected. Whether a word signals concession or contrast is a result of the argumentative purpose of the discourse (p. 93) ${ }^{8}$. For exam-

6 Bardenstein (forthcoming) discusses the meanings of the concessive connector afilu 'even' suggesting that it expresses category expansion so as to include extreme, peripheral or binary scenarios.

See also König (1986) and Haspelmath \& König (1998).

8 Shilo (2015) acknowledges the idea that some connectives mark both a contrast and a concession. Azar (1995: 140) presents an example of a concessive addition where the subordinate clause introduced by afilu 'even' functions as an additive. 
ple, but in $40 \%$ of the girls but $20 \%$ of the boys passed the test, marks a symmetrical relation of contrast as both parts are of equal status. However, in Studies checked the effect of parent employment on family well-being, but we checked for the first time the effect of employment of the children's education, the connective but displays a concessive asymmetrical relation between the two parts.

\section{Analysis of the construction $\operatorname{gam}^{9}$}

\subsection{Additive meaning}

This part of the article will examine various instances of polysemous gam as a reflection of a gradual continuum from the meanings of addition to concession. In line with construction grammar, we describe how these meanings arise as a result of an interaction between semantic, syntactic and pragmatic characteristics thereby creating a form-meaning pairing which constitutes part of the speaker's linguistic knowledge. It should be mentioned that even though all examples are taken from the same corpus, they are not restricted to one register. Rather, they represent a scale of formal and informal discourse. Our description is composed of six variants which contain one of the following alternatives: a single particle gam, a prepositional compound gam and a postpositional compound gam.

The definitions we rely on for the purpose of the analysis are as follows: Addition is expressed when a proposition of an equal or a greater status is added to an existing proposition, to a part of it or to an implied proposition. Concession is expressed when a causal relation is expected to be fulfilled or to occur between propositions. When it doesn't, or at least is presupposed not to occur, a meaning of incompatibility and therefore unexpectedness arises. We begin with cases which display explicit meaning of addition and are thus located at the additive end of the continuum ${ }^{10}$. It must be mentioned that although at first glance it seems that a clear meaning of addition is very common, the fact is that the majority of cases with gam do not express this expected meaning, but rather an implied concession. Consider the following examples ${ }^{11}$ :

1. Hashofetet daxata axat le'axat gam et sh'ar hata'anot shel Atias. the judge rejected one after another also ACC rest the arguments of Atias

'The judge rejected one after another the rest of Atias's arguments too.'

2. Ein safek shebahafaka haba'a tir'u oti gam.

no doubt that in the production next you will see me too

'There is no doubt that in the next production you will see me too.'

9 All examples are taken from HebrewCorpus: The National Middle East Language Resource Center (NMELRC) HebrewCorpus. Available at: http://hebrewcorpus.nmelrc.org [Last accessed: 06/05/2019]. The corpus consists over 150 million words and includes the Tanach, Mishnah, Israeli newspapers, early and modern fiction, movies subtitles, interviews from the Corpus of Spoken Israeli Hebrew, academic journals, Knesset sessions, Wikipedia and others.

10 See table 1.

11 As the purpose of this study is a description of the construction gam in Contemporary Hebrew, we shall not deal with various biblical uses as suggested by Kadari (2006), or such that are found mostly in $18^{\text {th }}$ century literature such as gam ki 'also because', af gam 'even also' and af gam zot 'even also this' (Even-Shoshan, 2010). 
3. Higati leEilat limtso avoda. Ani mehatsafon vesham ein xaim. I arrived in Eilat to find work. I am from the north and there there is no life.

Higati leEilat gam kedei limtso et atsmi le'axar nedudim bexol I arrived in Eilat also in order to find ACC myself after wandering all over the ha'arets. country.

'I arrived in Eilat to find work. I am from the north, where there is no life. I arrived in Eilat also to find myself after wandering all over the country.'

In sentence 1, the proposition contained in the phrase beginning with gam is added to a previously implied situation in which the judge already rejected other arguments of the defendant, thereby rendering both situations of a similar pragmatic nature. The phrase rest of the arguments further strengthens the idea that the previous arguments and the present ones are of the same value. Therefore, this is a case of a bare addition.

Sentence 2 could be interpreted in at least two ways. According to the first one, another performance is added to the one implied in the sentence. It is clear that the mentioned performance was indeed a big success and the audience expects a future repetition of the same success. On the other hand, a different reading may be attributed to the sentence, according to which the production referred to was accepted less favorably by the audience or the critics due to reasons such as lack of political correctness or other offending scenes. In this case, the speaker challenges them to the extent of provocation by promising that he is not giving in to the criticism and will also appear in the next production.

Both interpretations in sentence 2 depend entirely upon previous knowledge and understanding of the situation. In the first case, the meaning of addition is univocal as one performance is simply added to another one and is therefore placed at the additive end of the continuum. In the second reading, however, a second performance is added despite an implied rejection by the audience and the critics. This incompatibility between what is expected and what is presupposed to be realized is referred to as a concessive relationship. Although the first interpretation of gam is addition, one can see the underlying meaning of concession beginning to realize in certain pragmatic circumstances such as those presupposed in the second reading.

Example 3 conjoins two propositions; the first is finding a job in Eilat and the second is finding himself and discovering who he really is. The order of the propositions in this case indicates that finding a job is a primary goal although the speaker clearly states that he also wishes to find himself and thinks that Eilat would be the best place to do it. He explicitly says that no life exists in the north of the country. For him, finding a job is a prime necessity in order to further fulfill the second goal despite its possible high significance. However, under specific pragmatic circumstances, one might ascribe greater importance to finding one's self, thereby suggesting an implicated subtle meaning of concession; the speaker wishes to find a job and even aim higher in an attempt to find himself. The concession expressed in sentence 3 is different from the one expressed in sentence 2. While in 2, the incompatible added proposition creates a concessive relationship which could be paraphrased by although, in 3, the addition would be paraphrased by even, signaling an addition which is significantly more important.

A different type of addition is expressed through the connective ma gam 'what also' (all the more so), which indicates reinforcement (Quirk et al., 1985: 635): 
4. Lakahal she'ani meyatseg ein be'aya lehagi'a le'Eilat baxoref the public that I represent no problem getting to Eilat in winter

ma gam shebetkufa zo hamexirim nemuxim what also that at period this the prices are low

'The public I represent has no problem getting to Eilat in winter, all the more so as prices are lower that time of year.'

5. Hamenahel eino batu'ax shehatelevisya haxinuxit tetse niskeret the manager is not sure that the television educational will benefit

meha'ixud. Ma gam shehu ma'amin bepluralism betxum from the unification what also that he believes in pluralism in the area

hatikshoret. communication

'The manager is unsure that educational T.V. will benefit from the unification, all the more so as he believes in pluralism in communication.'

In example 4, the speaker, probably a travel agent, argues that it shouldn't be a problem to bring thousands of tourists to Eilat in winter. The speaker then proceeds with two supporting arguments: The first is that the clients he works with have no problem arriving in Eilat in the winter for reasons which are unspecified such as people practicing a liberal profession which allows taking a vacation at any given time. The second is that prices are low at this time of year. Semantically, the two propositions do not seem to be of an equal status as the first refers to the tourists and the second to the prices. Syntactically, the two propositions constitute complete sentences, each expressing a complete independent idea. While the syntactic relationship is completely parallel, the pragmatic one is unequal. An additional explanation is provided on top of a prior one, when the former may not be sufficient for the purpose of argumentation. Thus, adding the second argument regarding the prices is interpreted pragmatically as reinforcement or intensification for the purpose of convincing the hearer of the feasibility of bringing tourists in winter. In example 5, the speaker presents an argument regarding the lack of benefit of the reunion for the educational television and adds a second argument which expresses his belief in pluralism in the area of media.

In both 4 and 5, the speaker raises an argument that he perceives as insufficient to convince the hearer of its validity. He therefore adds a second argument typically considered as reinforcement. Oddly, this reinforcement may be interpreted as concession. In contrast to the expectation that the first argument should be sufficient, the speaker seems to believe that this is not the case. Whether the added proposition in fact further reinforces or not is entirely a pragmatic and a subjective evaluation. It is not at all obvious that this is the case.

\subsection{Intermediate cases}

The next group of expressions represents intermediate cases which display both addition and concession and appear to be the majority of the types of gam found in the corpus. The difference between the cases representing the additive end of the continuum and those representing intermediacy is that in the former addition 
is a dominant reading while in the intermediate cases, a clear distinction is not always easily perceived. The first type of intermediate cases is expressed through the connective gam kaxa 'also like this' (as it is). Consider the following examples:

6. Ani shokel lisgor et ha'esek. Lo shave li leha'asik 30 I am considering closing ACC the business. Not worth to me to keep 30 ovdim, gam kaxa anaxnu bekoshi sordim. workers also like this we barely survive

'I am considering closing the business. It is not worthwhile keeping 30 workers, we barely survive as it is.'

7. Eilat lo tsrixa lihiyot haxatser ha'axorit shel hamedina. Hahitmodeduyot Eilat not need to be the yard back of the country the confrontations haxinuxiyot be'Eilat gam kaxa maspik me'atgerot mibli shenosif educational in Eilat also like this enough challenging without adding

et sugiyat hacasino.

ACC the issue the casino

'Eilat should not be the back yard to the country. The educational confrontations in Eilat are challenging enough as it is without adding the issue of the casino.'

In example 6 addition is expressed through the employment of 30 people, a situation which exists alongside the already very difficult attempt of the business to survive. This addition however, is neither equative nor reinforcing in Quirk et al.'s terms (see section 2.2). The current situation of the business is described as very problematic and distressing through the proposition barely survive. As a result, the employment of 30 workers is perceived as superfluous to the extent that it creates unnecessary burden and distress. In example 7 it is the semantics of challenging enough which conveys the meaning that the addition of a casino will impose extra difficulty on the fragile educational system since significant confrontations already exist within it. One would not expect an employer to hire 30 employees when already striving to survive or a city to open a casino when already coping with educational challenges. As a result, the mere likelihood of an added distressing situation stands in contrast to the expected causal relationship leading to incompatibility and concession.

A second connective displaying both addition and concession is the compound gam ken 'also yes' (stressed):

8. Yalda ve'axiha ben ha- 8 xatsu et hakvish be'or yarok ubema'avar A girl and her brother age 8 crossed ACC the road in light green and in $\begin{array}{lll}\text { xatsaya. } & \text { Nahag otobus shepana yamina-gam ken be'or } \\ \text { pedestrian crossing } & \text { Driver bus who turned right also yes in light }\end{array}$ yarok- lo hivxin bashnayim upaga bayalda. in light green did not notice the two and hurt the girl

'A girl and her brother crossed the road in green light and in a pedestrian crossing. A bus driver who turned right-also in green light-did not notice the two and hurt the girl.' 
9. Hadietanit mamlitsa le'exol basar bakar pa'amaim beshavu'a. Nitan the dietician recommends eating meat beef twice a week Possible to le'exol basar bakar taxun, ktsitsot, bolonez, hamburger vaod. eat meat beef minced cutlets bolognaise hamburger etc Bekitniyot timtse'u gam ken barzel bekamuyot ktanot ve'af hen in legume you will find also yes iron in quantities small and too they are mumlatsot.

recommended

'The dietician recommends eating beef twice a week. You can eat minced beef, cutlets, bolognaise, hamburger etc. In legume too, you will find iron in small quantities and they are also recommended.'

In examples 8 and 9 , both addition and concession are expressed. In 8 , a bus driver is described to make an allegedly legitimate right turn. The connective gam ken signals the driver's right turn in green light as a legitimate act which follows another legitimate act-that of the children crossing in green light. However, a covert meaning of concession cannot be disregarded. The speaker presupposes the readers' experience with traffic rules, which should lead to the recognition that two concessive legitimate acts are not supposed to result in an accident. Yet, in complete contrast with this logic, the use of the connective signals that the sequence of two lawful acts, did in fact result unexpectedly in an accident. In other words, the causal relationship between obeying traffic rules and avoiding an accident was not obtained. The connective is then paraphrased as although and interpreted pragmatically as signaling this incompatible consequence ${ }^{12}$.

A similar integration of addition and concession is observed in sentence 9. The dietician recommends eating beef twice a week in order to get enough iron and lists several sources which provide it. He concludes that legume is also a recommended source of iron. The use of the connective gam ken here relies on the pragmatic presupposition held by the speaker regarding the hearer's knowledge about sources of iron. It is common knowledge that iron is found in red meat. Legume is less recognized by people as a source of iron. Had it been a known fact, the speaker would have simply used gam. As it is not, the connective aims to emphasize the fact that despite being contrary to expectation, legume is added to the recommended list. It is the particle ken (yes) in the connective which underscores the idea that legume is not merely an additional source of iron but also a less obvious one.

Other intermediate cases can be observed in the use of the particle gam whose additive meaning we already exemplified in 1-3. Consider the following examples:

12 This description is valid only in some counties and in accordance with local traffic rules. 
10. Ani nimshax lenashim mikol hagilim,

I am attracted to women of all ages

gam nashim bshelot bnot 35 yexolot la'asot li et ze.

also women mature aged 35 can do for me ACC this

'I am attracted to women of all ages, even 35-year-old mature women do it for me.'

11. Hayerukim vitru al hamu'amadut shelahem ba'ir. the green gave up the candidacy their in town kanir'e shegam hem hevinu sheyarok lo me'anyen af exad. probably that also they realized that green no interest no one

'The green ones gave up their candidacy in town. Even they probably realized that green is of no interest to anybody here.'

The connective gam conveys here both addition and concession. Addition is expressed in example 10 in the idea that the speaker admits being attracted to women of all ages, and women aged 35 and more are included and therefore added to this variety. The second reading implies that he can be attracted even to women aged over 35 in the sense of an extreme value as suggested by Harris (1988). The fact that the speaker chooses to mention the age range of 35 implies that this age would normally be out of expected range for the speaker. This unexpected choice is therefore pragmatically interpreted as an extreme case which extends the scale for mature women (and even very mature) which in turn can be paraphrased as even.

In example 11 both addition and concession can be identified. The speaker expresses the idea that in addition to the voters, the green party too, realized that green in fact interests nobody. The meaning of concession is conveyed pragmatically. The green party is not just any party which realized the lack of interest in green issues. Rather, it is even the green party who realized that, i.e. an extreme situation in terms of Harris. This interpretation is to be understood based on one's knowledge of parties and their agendas. One expects a party which promotes a specific issue to fully pursue it at almost any cost. A situation where a party does give up its candidacy for mayor occurs only at the extreme case where it realizes that its primary agenda and essence is of no interest to the public. It is this extreme end which allows the use of even in the translation and it is this extreme end which renders a concessive meaning of incompatibility and unexpectedness.

The next intermediate example illustrates the polysemy of the compound gam im (also if 'even if'):

12. Yeladim lotsrixim lishmo'a mesarim tsiniyim vedik'oniyim children not need to hear messages cynical and depressing

gam im mekoram bametsiut ha'amitit.

also if they originate in reality real

'Children do not need to hear cynical and depressing messages even if they originate in a real-life situation.' 
13. Adam gam im hu xole nefesh 'o mefager, hu metsape lekabel saxar a personalso if he sick mental or retarded he expects to get wages

holem tmurat avodato. appropriate for his work

'A person, even if he is mentally ill or retarded, expects to be paid appropriately for his work.'

In example 12 the use of the connective conveys both addition and concession. The proposition children do not need to hear messages which originate in a real-life situation is added to the implicit proposition children do not need to hear messages which originate in fictional or imaginative situations which is only pragmatically referred to. This addition is perceived as an extreme addition because according to the speaker even messages which are based on real-life situations are not a good enough reason in order for the parents to expose them to the children. This reading is entirely pragmatic as it is based solely on prior knowledge and subjective recommendation regarding the proper way to raise children. The pragmatically expected causal relationship suggesting that messages which originate in real-life situations should be exposed to the children does not exist here, resulting in incompatibility concession.

In example 13 the speaker expresses addition in the idea that similarly to all other people, a mentally ill person should also receive fair wages. However, the speaker is aware of the common prejudice suggesting that mentally ill people should be paid less than others due to fact that they might not do their job appropriately as required. The speaker strongly objects this position and argues that such people need to be paid equally, contrary to the common belief. The causal relationship expected by the hearer to obtain here does not exist resulting in incompatibility and concession.

As suggested by Quirk et al. (1985: 1099), the conditional concessive even if combines the concessive force of even and the conditional force of if. Thus in 12, the connective operates simultaneously to presuppose an addition of messages which originate in real-life situations to those which originate in fictional situations, leaving the option of real-life situations open. Similarly, in 13, the connective both presupposes a situation of a mentally ill person deserving equal pay, and at the same time leaves this option open. In both sentences, leaving options open suggests in fact that such cases may not materialize thereby emphasizing the pragmatically extreme nature of the added situation.

\subsection{Concessive meaning}

At the concessive stage of the continuum, we find cases which demonstrate the meaning of concession only, i.e. the additive meaning is eliminated. The next examples use the connector hagam she 'the also' (even though):

14. Imo hafxa le'ironit, hagam shexayu ben gva'ot Antoto, his mother became urbanite the also that they lived in the hills of Antoto

vekol da'agata hayta xinux yeladeha. and all her concern was education her children 
'His mother became an urbanite even though they were living in the hills of Antoto and all of her concern was about her children getting an education.'

15. Baxarnu betotseret ha'arets hagam she'ele mitotseret xuts we chose produce local the also that those produce foreign

hayu be'eixut tova yoter ubexatsi mexir. were of quality better and half price

'We chose local produce even though foreign produce was of a higher quality and half the price.'

The connector hagam in 14 conveys concessive meaning only. No addition is expressed here. The fact that the family lived in these hills is not added to any other proposition. Instead, there is a causal relationship which is not materialized. In other words, becoming an urbanite has occurred despite the living in the hills, thereby conveying the meaning of incompatibility and unexpectedness. This reading is obtained pragmatically due to one's prior knowledge regarding an explicit contrast between being an urbanite and living in the hills.

In example 15, the local product was preferred over a better and a less expensive foreign one. This causal relationship stands in complete contrast to factors which usually guide buyers and consumers. This unexpected preference conveys a clear meaning of concession.

The following example uses gam ken 'also yes' (stressed also) whose additive and concessive meanings were already dealt with in examples 8-9. Here, the connective conveys an extreme case of concession to the extent of a full contrast resulting in rejection:

16. Yoni lo mafsik lelaxlex al xaverim shelo. Gam ken xaver. Yoni doesn't stop defaming on friends his. Also yes friend

'Yoni doesn't stop defaming his friends. Some friend.'

17. Ze ma shehabaxur ose muli, kidum mexirot leproyekt this what that the guy is doing in front of me, promoting sales for project xinuxi. Gam ken derex leha'avir xufsha im hamishpaxa. educational also yes a way to pass holiday with the family

'This is what this guy is doing in front of me, promoting sales for an educational project. Some way to spend a family holiday.'

In example 16 concession is expressed in the idea that the person's behavior mentioned in the sentence is not the one expected from a friend and even stands in complete opposition with anticipated conduct. This meaning is obtained by placing the connective in the beginning of the sentence and stressing the particle gam. This connective is often used in cases where the speaker expresses doubts regarding the authenticity and sincerity of the situation. These doubts arise as a result of features or behavior which are completely untypical, unexpected and incompatible with the speaker's belief regarding the person or situation. 
In example 17, we find the same pattern of rejection. The sentence describes a salesman who is trying to promote sales while he is on holiday with his family. The speaker, witnessing the situation, perceives it as very awkward and extremely inappropriate for a vacation. The connective gam ken conveys the speaker's view regarding this inappropriateness and in fact expresses the idea of a complete rejection of such a behavior during a vacation.

In both 16 and 17 the use of gam ken (also yes 'stressed gam') can be described as an ironic tool to reject the described behavior. This irony is obtained through the complete rejection of the expected causal relationship and thus the opposition between the pragmatic reading and the literal semantic meaning.

It is important at this point to explain how the analysis of the gam construction demonstrates the advantages of the constructionist approach in accounting for polysemy in language. As stated by Tomasello (2003: 8), constructions are introduced into language in a gradual process. Through repetitive usage, constructions "emerge, evolve and accumulate modifications" (p. 14). We can see in the gam construction an example of the realization of this process. Independent components of lexical items such as gam im, gam kaxa and gam ken, whose meaning could presumable be analyzed in the past only compositionally, seem to have developed into "more tightly organized syntactic constructions" (p.14), evolving into form-meaning pairings. In light of this hypothesis, it could be assumed that occurrences of gam constitute one general construction which can be used to express addition, intermediacy and concession in a continuum, as they exhibit partial overlap and therefore polysemy. It is plausible that this general construction may further turn into discrete pairings eventually loosing the features mentioned.

\section{Conclusion}

As stated in the beginning, our main interest was to reveal the particular meanings of polysemous gam in each of the sentences. The findings which the analysis has yielded can be summarized in the following table which illustrates a possible continuous reading of the meanings of the construction gam:

Table 1. A continuum of the meanings of the construction gam.

\begin{tabular}{|c|c|c|c|c|c|c|c|}
\hline \multicolumn{2}{|c|}{ Addition } & \multicolumn{4}{|c|}{ Intermediate } & \multicolumn{2}{|c|}{ Concession } \\
\hline gam (also) & $\begin{array}{l}\text { ma gam } \\
\text { (what also) }\end{array}$ & $\begin{array}{l}\text { Gam kaxa } \\
\text { (also like } \\
\text { this) }\end{array}$ & $\begin{array}{l}\text { gam ken } \\
\text { (also yes) }\end{array}$ & $\begin{array}{l}\text { gam } \\
\text { (also) }\end{array}$ & $\begin{array}{l}\text { gam im } \\
\text { (also if) }\end{array}$ & $\begin{array}{l}\text { hagam } \\
\text { (the also) }\end{array}$ & $\begin{array}{l}\text { gam ken } \\
\text { (also yes) }\end{array}$ \\
\hline [addition] & [intensification] & [unex & ected, incor & mpatibl & a duntion] & [incompat & ble situation \\
\hline
\end{tabular}

According to the table, the different meanings along the continuum are expressed in terms of an interaction between addition and concession. The left end of the continuum presents cases where the dominant meaning is addition. The further the continuum progresses to the right of the continuum, the stronger the involvement of concession is perceived, to the point where concession gains supremacy at the very right end of the continuum and the notion of addition disappears completely. 
This continuum illuminates three important points regarding the meaning of gam. First, the findings described in this study support previous research on categorial classification. Categories are not discrete entities, and meanings are best understood as continuous and should be thus described more accurately in terms of more or less rather than existent or non-existent. As a result, there is often no clear borderline between different cases.

Second, placing the variants along the continuum seems to be the result of a complex process, namely the interaction between linguistic and pragmatic factors which in turn leads to a difficulty in differentiating addition from concession. As the analysis shows, meanings derive from the semantics and the pragmatics domains. Pragmatic meanings arise from presuppositions based on prior knowledge and experience of the interlocutors. Whereas addition is expressed when two propositions are perceived to be of a relatively equal status or value (which is also in part a pragmatic based perception), concession is obtained when two propositions cease to be of the same value, leading one to be recognized as essentially different, superior, out of the expected range, more important, extreme, reinforcing, superfluous or of a complete contrast. Establishing when these cases occur is to a large extent a pragmatic consideration. Therefore, we see cases at the left end of the continuum where the concessive meaning is only pragmatically implied while in the intermediate cases and those which are purely concessive, the variants of gam are coded as concession in that a recognizable concessive connective such as even and although or a contrastive connector at the far right end of the continuum can be used in place of the original expression.

Although most native speakers of Hebrew would agree on the readings suggested in the above analysis, pragmatic judgments may naturally vary leading to various interpretations. The more the background knowledge, values, beliefs and presuppositions are shared by interlocutors, the more judgments about interpretations tend to be unified. Hence, attempting a definite distinction between addition and concession would be almost futile and even an unproductive endeavor.

Third, the findings described in this study seem to be in accordance with the constructionist view of language. According to the analysis, an interaction of semantic, syntactic and pragmatic considerations results in particular meanings which are conventionally associated with each of the variants. These variants convey meanings which range from fully compositional (additive gam) to fully non-compositional (concessive hagam and gam ken). In non-compositionality we mean that relying on literal meanings of the lexical items realizing a variant does not yield the holistic conventional meaning associated with the pattern. At the same time however, the compositional structure does provide cues regarding the overall meaning (Traugott \& Trousdale, 2013). As these patterns cannot be accounted for only in terms of syntax or semantics, the constructionist approach, unlike others, pays special attention to incorporating contextual factors which combine to create "an integrated whole" (Fried, 2013: 422). Such a description more accurately transmits that piece of the speaker's linguistic knowledge represented by a construction. Furthermore, the analysis provides support for the idea that the present-day characteristics of the various expressions of gam may be viewed as a result of constructionalization. 


\section{References}

Anderson, S.R., (1982) “Where’s morphology?” in Linguistic Inquiry. Vol. 13, n4, pp. 571612.

Athanasiadou, A., (2007) “On the subjectivity of intensifiers” in Language Sciences. Vol. 29, pp. 554-565.

Azar, M., (1995) The syntax of Mishnaic Hebrew. Jerusalem, The academy of the Hebrew language and University of Haifa. (In Hebrew).

Azar, M., (1999) "On the concessive in Contemporary Hebrew” in Sharvit, S. (ed.), Studies on the ancient and Contemporary Hebrew. Ramat Gan, Bar-Ilan University, pp. 285-304. (In Hebrew).

Bardenstein, R., (forthcoming 2019) “The Grammaticalization of afilu 'even', from an unreal conditional phrase to a discourse marker of argumentative strengthening" in Helkat Lashon. Vol. 53. (In Hebrew).

Bat Zeev Shyldkrot, H., (1995) "Subordonnées circonstancielles et dépendance sémantique. Comparison, concession et condition: grammaticalization et sens des connecteurs" in Faits de Langues. №5, pp. 145-154.

Bat-Zeev Shyldkrot, H., (2001) "Grammaticalisation et valeur sémantique : à propos d'un emploi particulier de même" in Buridant, C., Kleiber, G. \& J. C. Pellat (éds.), Par monts et par vaux. Itinéraires linguistiques et grammaticaux. Louvain, Peeters, pp.1-14.

Croft, W., (2001) Radical Construction Grammar. Syntactic Theory in Typological Perspectives. Oxford, Oxford University Press.

Croft, W. \& D. A. Cruse, (2004) Cognitive Linguistics. Cambridge, Cambridge University Press.

Even-Shoshan, A., (2010) The new dictionary. Jerusalem.

Fillmore, C.J., (1975) "An alternative to checklist theories of meaning" in Proceedings of the First Annual Meeting of the Berkeley Linguistics Society [Online], pp. 123-131. DOI: http://dx.doi.org/10.3765/bls.v1i0.2315 [Last accessed: 06/05/2019].

Fillmore, C.J., (1988) "The mechanisms of Construction Grammar" in Proceedings of the Fourteenth Annual Meeting of the Berkeley Linguistics Society [Online], pp. 35-55. DOI: http://dx.doi.org/10.3765/bls.v14i0.1794 [Last accessed: 06/05/2019].

Fried, M., (2013) "Principles of Constructional Change" in Hoffmann, T. \& G. Trousdale (eds.), The Oxford handbook of construction grammar. Oxford, University Press, pp. 419437.

Goldberg, A. E., (1995) Constructions. A construction grammar approach to argument structure. Chicago/London, The University of Chicago Press.

Goldberg, A. E., (2003) "Constructions: a new theoretical approach to language" in TRENDS in Cognitive Science. Vol. 7, $\mathrm{n}^{\circ} 5$.

Goldberg, A. E., (2006) Constructions at work: the nature of generalization in language. Oxford, Oxford University Press.

Goldberg, A. E., (2013) “Constructionist approaches” in Hoffmann, T. \& G. Trousdale (eds.), The Oxford handbook of construction grammar. Oxford, Oxford University Press, pp. 15-31.

Goldberg, A. E. \& J. van der Auwera, (2012) "This is to count as a construction" in Folia Linguistica. Vol. 46, n¹, pp. 109-132.

Harris, M., (1986) "The historical development of the conditional sentences in Romance" in Romance Philology. Vol. 39, nº4, pp. 405-436.

Harris, M., (1988) "Concessive clauses in English and Romance" in Haiman, J. \& S. Thompson (eds.), Clause combining in grammar and discourse. Amsterdam/Philadelphia, John Benjamins, pp. 71-100. 
Haspelmath, M. \& E. König, (1998) "Concessive conditionals in the languages of Europe" in van der Auwera, J. (ed.), Adverbial constructions in the languages of Europe. (Empirical approaches to language typology/EUROTYP, 20-3). Berlin, Mouton de Gruyter, pp. 563640.

Hilpert, M., (2014) Construction grammar and its application to English. Edinburgh, Edinburgh University Press.

Hoffmann, T. \& G. Trousdale, (2013) "Construction grammar: Introduction" in Hoffmann, T. \& G. Trousdale (eds.), The Oxford handbook of construction grammar. Oxford, University Press, pp. 1-14.

Kadari, M., (2006) Dictionary of Biblical Hebrew. Ramat Gan, Bar-Ilan University. (In Hebrew).

Kay, P., (2004) "Pragmatic aspects of grammatical constructions" in Laurence, H. \& G. Ward (eds.), The handbook of pragmatics. Malden, Oxford \& Carlton, Blackwell, pp. 675-700.

Kong, K., (2014) Professional Discourse. Cambridge University Press.

König, E., (1985) "On the history of concessive connectives in English. Diachronic and synchronic Evidence" in Lingua. Vol. 66, nº1, pp. 1-19.

König, E., (1986) "Conditionals, concessive conditionals and concessive: Areas of contrast, overlap And Neutralization" in Traugott, E.C. et al. (eds.), On Conditionals. Cambridge, Cambridge university Press, pp. 229-246.

Lakoff, G., (1987) Women, fire and dangerous things. What categories reveal about the mind. Chicago/London, The University of Chicago Press.

Langacker, R., (2008) Cognitive Grammar: A Basic Introduction. Oxford, Oxford University Press.

Langacker, R., (2013) Essentials of cognitive Grammar. Oxford, Oxford University Press.

Livnat, Z., (2010) Rhetoric of the scientific article. Language and the discourse community. Ramat Gan, Bar Ilan University Press. (In Hebrew).

Mann, W.C. \& S.A. Thompson, (1988) "Rhetorical structure theory: Toward a functional theory of text organization" in Text-Interdisciplinary Journal of Discourse. Vol. 8, n³, pp. 243-281.

Narrog, H., (2017) "Three types of subjectivity, three types of intersubjectivity, their dynamicization and a synthesis" in Van Olmen, D., Cuyckens H. \& L. Ghesquière (eds.), Aspects of grammaticalization. Berlin/Boston, Mouton De Gruyter, pp. 19-46.

Noël, D., (2007) "Diachronic construction grammar and grammaticalization theory" in Functions of Language. Vol. 14, n², pp. 177-202.

Quirk, R. et al. (eds.), (1985) A comprehensive grammar of the English language. London, Longman.

Rosch, E.H., (1973) "Natural categories" in Cognitive Psychology. Vol. 4, pp. 328-350.

Ross, J.R., (1972) “The category squish: Endstation Hauptwort" in Chicago Linguistic Society. Vol. 8, pp. 316-328.

Ross, J.R., (1973) "Nouniness" in Fujimura, O. (ed.), Three dimensions of linguistic theory. Tokyo, TEC Corporation, pp. 137-258.

Rudolph, E., (1996) Contrast. Adversative and concessive expressions on sentence and text level. Berlin/New York, De Gruyter.

Shefer, H., (2018) “The meaning and development of Hebrew scalar modifier kexol" in Topics in Linguistics. Vol. 19, n², pp. 38-56.

Shilo, G., (2015) "Concessive and conditional connectives in Hebrew" in Bat-Zeev Shyldkrot, H., Bertin, A. \& O. Soutet (eds.), Subordonnants et Subordination à Travers les Langues. Paris, Champion, pp. 159-188. 